\title{
FINANCIAMENTO DA SAÚDE E PACTO FEDERATIVO
}

\section{Diego Losada Vieitez ${ }^{1}$ Ana Helena Scalco Corazza ${ }^{2}$}

\begin{abstract}
Resumo:
A prestação de serviços públicos de saúde está estruturada em um Sistema Único, no qual participam financeiramente e têm competências próprias todos os entes federados. O presente estudo aborda o problema de entender duas de suas principais disfunções: a participação relativa cada vez menor da União no financiamento, e o conflito gerencial entre controle pela União e autonomia dos Municípios. O objetivo é traçar um panorama compreensivo da evolução histórica desses problemas e apresentar propostas corretivas. O método de abordagem será o hipotético-dedutivo, o método de procedimento será o monográfico.
\end{abstract}

Palavras-chave: Direito Fundamental à Saúde; pacto federativo; financiamento da saúde; piso mínimo de gastos; transferências financeiras.

\section{HEALTH FINANCING AND FEDERATIVE PACT}

\begin{abstract}
:
The provision of public health services is structured in a single system, in which all federative entities participate financially and have their own competencies. The present study addresses the problem of understanding two of its main malfunctions: the Union's declining relative participation in financing, and the administrative conflict between control by the Union and the autonomy of municipalities. The objective is to draw a comprehensive picture of the historical evolution of these problems and to present corrective proposals. The method of approach will be hypothetic-deductive, the procedure method will be monographic.
\end{abstract}

Keywords: Fundamental Right to Health; Federative Pact; Health Financing; Minimum Amount of Spending; financial transfers

\section{INTRODUÇÃO}

A institucionalização do Sistema Único de Saúde-SUS pela Constituição Federal de 1988-CF/88 representou um marco para as políticas públicas de saúde no país. O referido direito social fundamental foi definido como um direito de todos e um dever do Estado, que deve garanti-lo por meio de políticas sociais e econômicas. O SUS consagrou uma ruptura em

\footnotetext{
${ }^{1}$ Mestrando do PPGD em Direito da Pontifícia Universidade Católica do Rio Grande do Sul. Auditor público externo do Tribunal de Contas do Estado do Rio Grande do Sul.

${ }^{2}$ Mestranda do PPGD em Direito e Políticas Públicas da Universidade de Santa Cruz do Sul. Auditora pública externa do Tribunal de Contas do Estado do Rio Grande do Sul.
} 
relação ao modelo de prestação de saúde pública anterior a abertura democrática que atendia apenas à população vinculada ao mercado de trabalho formal, excluindo boa parte da sociedade do acesso aos referidos serviços públicos ${ }^{3}$. A $\mathrm{CF} / 88$, portanto, universalizou o direito à saúde, de forma que todos os brasileiros teriam direito de receber assistência estatal, dentro de uma rede regionalizada e hierarquizada.

Registra-se que o crescimento exponencial da positivação de diretos fundamentais por meio da Constituição Cidadã, ora por princípios gerais, ora por regras específicas, veio como resposta aos anseios populares de consagração de direitos. Entretanto, tal fenômeno resultou em uma forte pressão social, política e institucional quanto à forma de utilização dos recursos públicos e quanto à elaboração e execução orçamentaria dos entes federados, levando-se em conta especialmente que o Brasil é um Estado Democrático Fiscal, o qual extrai a maior parte seus recursos da própria sociedade, mediante tributação.

Ou seja, em face da institucionalização do SUS e do incremento de posições jurídicas aos cidadãos, a conjectura normativa pós 1988 caminhou no sentido de se estabelecer um financiamento estatal mínimo do direito à saúde, o qual foi estruturado em um sistema de responsabilidade compartilhada pelos três níveis federativos, conforme esquema inovador e revolucionário desenhado constitucionalmente. Entretanto, já nesta quadra da história, passados quase 30 anos da promulgação da Lei Fundamental, não se vislumbra a existência de regras adequadas atinentes ao equilíbrio federativo de financiamento da saúde, ainda que incessantemente o sistema venha sendo objeto de reformas e melhoramentos.

Com efeito, a estrutura arrojada que se deu ao SUS, que deveria ter ampla participação integrada dos três níveis, conforme princípios de universalidade, integridade e

3 Anteriormente ao SUS, a prestação de serviços públicos de saúde se dava, principalmente, dentro do sistema previdenciário contributivo organizado pelo Ministério da Previdência e Assistência Social-MPAS e estruturado no Instituto Nacional de Assistência Médica da Previdência Social-Inamps, ambos datados de 1974. Assim, os atendimentos eram limitados aos trabalhadores formais com carteira assinada e seus dependentes registrados, e realizados em estabelecimentos públicos ou privados conveniados. O Ministério da Saúde e as Secretarias de Estado da Saúde atuavam na área também, mas apenas na prevenção e no atendimento de doenças de risco ou contagiosas; ou seja, em serviços voltados para a sociedade como um todo, em vez de para os indivíduos como unidade. Desse modo, as pessoas sem cobertura previdenciária dependiam principalmente das entidades religiosas ou filantrópicas de assistência. Além disso, havia casos não-estruturados e não-sistêmicos de estados e municípios prestando atendimento mais direto da saúde. Diante desse cenário de insuficiência, foram sendo feitas implementadas propostas progressivamente mais amplas de formação de uma rede de serviços para a atenção primária de saúde como o Programa de Interiorização das Ações de Saúde e Saneamento-PIASS, de 1976, o Ações Integradas de Saúde-AIS, de 1984, e o Sistema Unificado e Descentralizado de Saúde-SUDS, de 1987. Destaca-se ainda a histórica $8^{a}$ Conferência Nacional da Saúde, realizada em março de 1986, que consagrou os princípios do Movimento da Reforma Sanitária. Essas iniciativas são a origem do atual Sistema Único de Saúde - SUS. 
equidade, representou uma ruptura muito grande com o modelo anterior, conforme exposto, porém não suficientemente trabalhada, tanto em âmbito gerencial quanto financeiro, sendo necessário que se insira racionalidade a esta política pública e às suas formas de suporte financeiro, por meio de propostas que esse ensaio apresentará.

Com base nesse escopo, o objetivo geral do presente estudo consiste em trazer algumas luzes a um problema complexo que pode ser abordado em dois principais conflitos na relação entre financiamento da saúde e pacto federativo, quais sejam: a repartição do ônus do custeamento entre os três níveis federativos, desde 1989 até meados de 2017; e o conflito gerencial que se passa nos direcionamentos pela União nas verbas repassadas aos demais entes em face da autonomia dos Municípios brasileiros.

Dado esse contexto, as hipóteses que apresentam e se espera confirmar é que o SUS sofre de subfinanciamento, que há uma crescente participação relativa menor da União em relação aos Municípios (o que se buscou deter por meio de normatização, culminando com a EC 86) e que há um conflito gerencial federativo interno no SUS, com a União buscando maior controle e os Municípios maior autonomia. Destarte, considerando que o direito à saúde é hoje tema central da pauta estatal relativa às políticas públicas - o qual deve necessariamente ser pensado dentro do cenário político-econômico brasileiro que perpetua diariamente corriqueiros retrocessos em direitos sociais e previdenciários com amparo em argumentos orçamentários - é que a presente pesquisa se justifica socialmente.

Para o desenvolvimento da pesquisa, as diretrizes metodológicas partirão do método de abordagem hipotético-dedutivo, visando o processo de confirmação ou falseamento das hipóteses lançadas, no sentido de que possíveis saídas para o problema do subfinanciamento do SUS não estão centradas precipuamente na estipulação de mais impostos vinculados, mas sim por um (re)olhar para as políticas públicas de saúde, adequando-as a longo prazo (relação entre a quantidade de prestações com a de recursos disponíveis) e pela consideração de que as normas regulamentadoras atuais não atenuam o desequilíbrio de financiamento do SUS. Já o método de procedimento será o monográfico e as técnicas de pesquisa constituirão na consulta a fontes primárias e secundárias, isso é, na legislação e na produção técnica, bem como na doutrina (livros e revistas científicas) existente sobre os temas tratados.

\section{GÊNESE, EVOLUÇÃO E OS PROBLEMAS DA REPARTIÇÃO DO FINANCIAMENTO DA SAÚDE}


Bonavides (2016), ao tratar do Constitucionalismo do Estado Social, refere-se às Constituições brasileiras de 1934, 1946 e 1988, sustentando que estas assinalam o primado da Sociedade sobre o Estado e o indivíduo, ou seja, fizeram do homem o destinatário da Constituição. Assim, a CF/88 é, em muitas de suas dimensões, uma Constituição do Estado social, devendo ser reconhecida a dependência do indivíduo em relação às prestações do Estado e a necessidade de este último cumprir a sua tarefa igualitária e distributiva sem a qual não haverá democracia e tampouco liberdade.

\title{
2.1 O Direito Fundamental Social à Saúde
}

Não pairam dúvidas, desta feita, quanto ao fato de que a Constituição Federal de 1988 adotou um modelo de Estado Social e Democrático de Direito, consagrando ao cidadão brasileiro, expressamente, uma vasta positivação de posições jurídico-subjetivas de caráter social, o que, invariavelmente, atribuiu ao Estado deveres da mesma natureza, delineando aquilo que Hachem (2013, p. 345) apontou como “Administração Pública inclusiva”. Nesse sentido:

\begin{abstract}
A Lei Fundamental de 1988 [...] operou verdadeira revolução no Direito Público nacional. Afinado com as transformações experimentadas pelo Direito Constitucional na Europa continental a partir da segunda metade do século XX, em um fenômeno denominado por alguns de "neoconstitucionalismo", o constitucionalismo brasileiro também muda de feição. Da superioridade da lei formal passa-se à supremacia da Constituição, que se converte em parâmetro de validade do conteúdo material de todas as demais normas, por condensar valores sociais mais importantes, correspondentes aos princípios de justiça compartidos pela sociedade, de observância obrigatória não só ao legislador, mas também ao juiz e à Administração". (HACHEM, 2013, p. 348).
\end{abstract}

O mesmo autor pondera que uma definição contemporânea de desenvolvimento deve levar em consideração diversas dimensões que não se restringem à esfera econômica de um Estado. Há uma interdependência entre a esfera humana e social, o que distingue a noção de desenvolvimento da noção de crescimento. O desenvolvimento, nos dias de hoje, portanto, além do aumento quantitativo do produto nacional, reclama transformações estruturais socioeconômicas que importem a melhora qualitativa dos padrões de vida dos cidadãos, proporcionando a elevação do bem-estar social (HACHEM, 2013, p. 382).

Ocorre que, conforme dispõe Maurício Jr (2009, p. 19), o Estado brasileiro não se reconduz a um Estado patrimonial, que financia as suas despesas através da exploração do 
próprio patrimônio, como ainda ocorre, por exemplo, nos Estados petrolíferos, eis que é um

Estado Democrático e Social eminentemente Fiscal, que extrai recursos de que necessita mediante a tributação de riqueza da própria sociedade. Isso significa, em síntese, que quem financia efetivamente as prestações positivas estatais são os contribuintes, devendo-se evitar uma visão isolada dos direitos sociais como oriundos do dever Estatal de socialidade:

Fornecer prestações estatais equivale a realizar despesa pública, e a Constituição dedica integralmente o Capítulo II do Título VI à disciplina dos gastos públicos, colocando o orçamento no centro do processo governamental de alocação de recursos. Assim, se os direitos têm custos e se desenvolvem na medida das disponibilidades de recursos públicos, o orçamento passa a ocupar uma posição central na implementação de políticas ligadas à realização de direitos á prestações estatais. (MAURÍCIO Jr, 2009, p. 20-21) ${ }^{4}$.

Com efeito, a política pública de saúde, conforme arranjo constitucional disposto na $\mathrm{CF} / 88$, "revela-se como produto maturado - embora inconcluso [...] de um longo e construtivo processo de transformação social, com fundas raízes democratizantes" (PINTO; FLEURY, 2012, p. 65). E, em não constando o detalhamento necessário do arranjo do financiamento público do SUS junto ao texto constitucional, foi este sendo construindo por uma sucessão de normas em paralelo com reajustes orçamentários.

\subsection{Histórico Geral das Normas de Financiamento da Saúde na Ordem Constitucional de 88}

Inicialmente, a CF/88 contemplou apenas regra de que haveria participação dos três níveis federativos no financiamento dos serviços públicos ${ }^{5}$. Destarte, o $\$ 1^{\circ}$ do art. 198

\footnotetext{
$4 \mathrm{O}$ tema dos custos dos direitos - presente não somente nos direitos prestacionais mas também no de liberdade política, dada a necessidade de manter instituições e agentes públicos de policiamento e jurisdição - já de longa data está presente no debate sobre direitos fundamentais, principalmente sob a ótica da reserva da possível. Contudo, vem ganhando novo destaque com o estudo do custo das escolhas que residem no centro de uma estrutura estatal por Holmes e Sunstein (1999).

${ }^{5}$ Art. 198. As ações e serviços públicos de saúde integram uma rede regionalizada e hierarquizada e constituem um sistema único, organizado de acordo com as seguintes diretrizes: [...] $\S 1^{\circ} \mathrm{O}$ sistema único de saúde será financiado, nos termos do art. 195, com recursos do orçamento da seguridade social, da União, dos Estados, do Distrito Federal e dos Municípios, além de outras fontes. (Parágrafo único renumerado para $\S 1^{\circ}$ pela Emenda Constitucional $\mathrm{n}^{\circ} 29$, de 2000) $\S 2^{\circ}$ A União, os Estados, o Distrito Federal e os Municípios aplicarão, anualmente, em ações e serviços públicos de saúde recursos mínimos derivados da aplicação de percentuais calculados sobre: (Incluído pela Emenda Constitucional n ${ }^{\circ} 29$, de 2000) I - no caso da União, a receita corrente líquida do respectivo exercício financeiro, não podendo ser inferior a 15\% (quinze por cento); (Redação dada pela Emenda Constitucional n ${ }^{\circ} 86$, de 2015) II - no caso dos Estados e do Distrito Federal, o produto da arrecadação dos impostos a que se refere o art. 155 e dos recursos de que tratam os arts. 157 e 159, inciso I, alínea a, e inciso II, deduzidas as parcelas que forem transferidas aos respectivos Municípios; (Incluído pela
} 
positivou que o financiamento para a saúde fosse aportado, nos termos do art. 195, com recursos do orçamento da seguridade social, da União, dos Estados, do Distrito Federal e dos Municípios, além de outras fontes, sem estabelecer percentual mínimo.

Já a Emenda Constitucional n ${ }^{\circ} 29$, de $2000^{6}$, discriminou a origem dos recursos que financiariam a saúde sob responsabilidade dos entes federados (art. 198, § 2º II e III, da CF, conforme nota de rodapé 3), estabelecendo as bases para a participação mínima de cada ente federado, e dispôs acerca da necessidade de edição periódica de lei complementar para fixar e revisar os percentuais de vinculação dos recursos destinados às ações e serviços públicos de saúde por parte dos entes federados, assim como para estabelecer os critérios de rateio, de fiscalização de controle dos recursos (vide art. 198, $\$ 3^{\circ}$, da CF). Ou seja, foram determinados quais fontes tributárias sustentariam a saúde, mas não estabelecido o percentual mínimo de cada uma delas que deveria ser aplicado. Sobre o ponto, minudente análise:

Em face da crise econômica premente em 1999 e 2000, soou como circunstancialmente justificável a falta de disposição direta no texto permanente da Constituição dos patamares mínimos de gasto público em saúde, na forma do parágrafo $2^{\circ}$ do Art. 198, introduzido pela EC $\mathrm{n}^{\circ}$ 29. Passados dez anos da promulgação dessa Emenda e cinco anos depois de esgotada a fórmula transitória do Art. 77 do ADCT, o financiamento estatal das ações e serviços públicos de saúde ainda se ressentia da técnica legislativa adotada na circunstância histórico-política da edição da Emenda no 29. (PINTO; FLEURY, 2012, p. 66).

Com efeito, a EC no 29/2000 somente foi regulamentada em janeiro de 2012 por meio da Lei Complementar $n^{\circ} 141 / 2012$, que finalmente definiu de forma expressa, no seu art. $1^{\circ}$, o valor mínimo e normas de cálculo do montante a ser aplicado, anualmente, pela União, e os percentuais o produto da arrecadação de impostos a serem aplicados anualmente pelos

Emenda Constitucional n ${ }^{\circ} 29$, de 2000) III - no caso dos Municípios e do Distrito Federal, o produto da arrecadação dos impostos a que se refere o art. 156 e dos recursos de que tratam os arts. 158 e 159 , inciso I, alínea b e $\S 3^{\circ}$. (Incluído pela Emenda Constitucional n ${ }^{\circ} 29$, de 2000) $\S 3^{\circ}$ Lei complementar, que será reavaliada pelo menos a cada cinco anos, estabelecerá:(Incluído pela Emenda Constitucional $\mathrm{n}^{\circ}$ 29, de 2000)I - os percentuais de que tratam os incisos II e III do $§ 2^{\circ}$; (Redação dada pela Emenda Constitucional n ${ }^{\circ} 86$, de 2015) II - os critérios de rateio dos recursos da União vinculados à saúde destinados aos Estados, ao Distrito Federal e aos Municípios, e dos Estados destinados a seus respectivos Municípios, objetivando a progressiva redução das disparidades regionais; (Incluído pela Emenda Constitucional $n^{\circ} 29$, de 2000) III - as normas de fiscalização, avaliação e controle das despesas com saúde nas esferas federal, estadual, distrital e municipal; (Incluído pela $\underline{\text { Emenda Constitucional } \mathrm{n}^{\circ} \text { 29, de 2000) }}$ IV - (revogado). (Redação dada pela Emenda Constitucional $\mathrm{n}^{\circ}$ 86, de $\frac{2015) \text {. }}{6}$

Assim, com a edição da EC n 29/2000, estabeleceram-se patamares mínimos de aplicação de recursos financeiros na saúde por parte das três esferas governamentais. Até 2004, Estados e municípios seriam obrigados a investir, no mínimo, $12 \%$ e $15 \%$ da arrecadação de seus impostos próprios, respectivamente. A União, desde então, deveria gastar com saúde o correspondente ao que desembolsou no ano anterior, corrigido pela variação nominal do Produto Interno Bruto. Na ausência da referida lei complementar, a CF/88 determinou ainda que fossem mantidas as regras transitórias vigentes até 2004 (art. 77, §4 ${ }^{\circ}$ do ADCT). 
Estados, pelo Distrito Federal e pelos Municípios em ações e serviços públicos de saúde. Além disso, a Lei Complementar no 141/2012 ainda descreveu quais despesas poderiam ser consideradas como sendo de "ações e serviços públicos de saúde", resolvendo outra celeuma que vinha se arrastando, pois alguns entes escrituravam como sendo de saúde dispêndios que nem todos classificavam desta maneira, como os de nutricionista escolar ou de varrição urbana.

Essa normatização importou na aplicação do piso constitucional, podendo-se a partir daí conferir eficácia à EC no 29/2000, e garantir um mínimo de financiamento permanente para o setor. Nesse sentido, pode-se dizer que a LC $n^{\circ}$ 141/2012, introduziu um componente qualitativo na análise do gasto de saúde, com a fixação de regras, diretrizes e condições para identificação de despesas passíveis de serem consideradas como "ações e serviços públicos de saúde", reduzindo-se a subjetividade nas definições e contribuindo para aproximar as despesas do setor à intenção original do constituinte da $\mathrm{EC} \mathrm{n}^{\circ} 29$, de 2000.

\subsection{Lições Históricas: Problemas na Inclusão da Saúde dentro da Seguridade Social, e na Criação de Tributos para Financiamento Exclusivo}

Como exposto, quando da promulgação da Carta Constitucional de 88 não havia regras detalhadas sobre como se daria o financiamento da saúde dentro dos três níveis federativos. Tais especificações ocorreram em longo processo de evolução normativa, por tentativa e erro, todas tateando por um projeto de pacto federativo e pelos limites fáticos de recursos

Nesse sentido, como ainda hoje se buscam soluções para o problema do financiamento do SUS, o exame histórico é bastante elucidativo para o estabelecimento de planos futuros. Passam-se, então, por oportuno, a destacar dois pontos identificados no curso desta pesquisa que já deveriam ser do conhecimento dos atuais operadores jurídicos como sendo problemáticas, mas que talvez ainda não tenham sido absorvidas no nível necessário. Tais pontos são ainda relevantes para as questões tratadas posteriormente no presente estudo sobre financiamento da saúde e pacto federativo.

Primeiro, cabe discutir a colocação da saúde como sendo parte da Seguridade Social. Nesta ordem constitucional, o orçamento público passou a ser dividido em três peças, como previsto no art. $165, \S 5^{\circ}$ : orçamento fiscal (todas as receitas e despesas dos Poderes, fundos, órgãos e entidades que não estiverem nas outras duas peças), orçamento de investimento das 
empresas públicas, e orçamento da seguridade social (contemplando saúde, assistência social e previdência).

Portanto, a partir de 1988 a saúde passou a competir diretamente por recursos com a assistência social e a previdência. Esse arranjo logo se revelou instável, pois já em 1993 o desequilíbrio financeiro foi de tal monta que deixaram de haver recursos no orçamento para a saúde. Como primeira forma de resolver essa situação, logo naquele ano foi editada a Medida Provisória n. 364/93, convertida na Lei Federal n. 8.736/93, pela qual os recursos do Fundo de Amparo ao Trabalhador (FAT) foram transferidos para saúde em troca da emissão de títulos da dívida pública para aquele Fundo; tal situação de viria a se prolongar ainda por muitos anos.

Tal problema decorrente da mistura do financiamento da saúde com o da previdência já era conhecido antes; como reporta Miranda Filho (1995), tendo sido instituída no Congresso Nacional a Comissão Especial para Estudo do Sistema Previdenciário, consignando o relatório final, do Deputado Antônio Britto, “o grande erro dos constituintes na adoção irrefletida do conceito de 'seguridade social' previsto pela OIT sem quaisquer ressalvas no que concerne à separação das fontes de custeio e financiamento da previdência, saúde e assistência". Chegou-se então a seguinte conclusão naquele estudo:

\footnotetext{
“A seguridade social acaba presa a um perigoso círculo vicioso, onde as pressões da saúde em termos de recursos têm como vítima a Previdência, esta, a saúde e ambas à assistência social, quando o correto seria a discussão de prioridade no País, a busca de maior participação de recursos fiscais e a contestação, por exemplo, da utilização de fontes da seguridade social para pagamento dos aposentados do Governo. Não são outras as preocupações do ilustre Dep. José Lourenço, ao propugnar por uma separação completa das fontes de financiamento da Previdência, para que assim possa se reestabelecer seu equilíbrio atuarial".
}

Também é importante notar que a integração constitucionalmente prevista, a qual consagrou a saúde como parte integrante de um sistema de seguridade social ao lado da previdência e da assistência social, só teria funcionado de forma adequada se tivesse havido além de um orçamento conjunto, uma gestão efetivamente una, que priorizasse a todos.

Entretanto, as três subáreas, previdência, saúde e assistência social foram gradativamente regulamentadas por leis distintas e institucionalizadas em ministérios respectivos, com receitas igualmente estipuladas de forma separada. Em suma, operou-se uma quase completa "independência administrativa e financeira, não obstante o sistema em sua origem tivesse forte apelo à criação de um único ministério, financiado por um orçamento da seguridade social, autônomo do orçamento fiscal e estabelecido por um conselho nacional" 
(SENADO FEDERAL, 2013, p. 13) ${ }^{7}$. Havendo então a independência, e consequente competitividade entre as áreas, inevitável que o resultado fosse a disfunção já exposta.

Um segundo ponto de lição histórica que vale esclarecer foi a experiência de criação de tributo específico para custeio da saúde. Com efeito, havia uma situação grave de insuficiência de recursos repassados para saúde (especialmente com o consumo de valores da seguridade pela previdência). Para resolver isso, em 1996 se decidiu adotar a Contribuição Provisória sobre Movimentação ou Transmissão de Valores e de Créditos e Direitos de Natureza Financeira (CPMF). Para criar tal fonte de financiamento da saúde, o Congresso Nacional promulgou a Emenda Constitucional $n^{\circ}$. 12, de 15 de agosto de 1996, e a regulamentou pela Lei n9.311, de 24 de outubro de1996.

Inobstante, a medida adotada pelo Parlamento não aumentou a participação de recursos na saúde, pois o estudo da evolução das despesas aplicadas em saúde mostra apenas que, havendo uma fonte segura de recursos vinculados, os gestores públicos deixaram de alocar recursos livres para tal fim. Ou seja, "a contribuição imediata da CPMF foi mais efetiva para a garantia de estabilidade de financiamento da saúde do que para a ampliação de seus recursos, uma vez que seu impacto foi amortecido pela retração de outras fontes de financiamento da saúde" (PIOLA, 2013). Desse modo, a CPMF acabava por não custear a saúde, mas apenas permitir que recursos que seriam da saúde fossem alocados para outros fins, fazendo portanto custeio indireto de outras áreas.

Vale ainda destacar que tendo a CPMF sido vista como uma fonte segura de recursos, os governos buscaram subsequentemente ampliar sua vigência com sucessivas prorrogações: sua vigência foi reestabelecida pelas Emendas Constitucionais n ${ }^{\circ}$. 21/1999 (pela qual passou a custear também aposentadorias, pensões e combate a pobreza), $n^{\circ}$. 37/2002 e $\mathrm{n}^{\circ}$. 42/2003. Foi ainda apresentada a PEC n ${ }^{\circ}$. 89/2007 buscando outra prorrogação, mas não foi aprovada. O conhecimento dos efeitos que a instituição da CPMF provocou, enquanto esteve vigente, é bastante relevante no momento atual, em que ainda se apresentam propostas para recriá-la ${ }^{8}$.

7 Como exemplo desse movimento, pode-se citar a edição da EC n 20/1998, que modificou o art. 167, XI, foi vedada a utilização dos recursos provenientes das contribuições sociais de que trata o art. 195, I, a, e II, para a realização de despesas distintas do pagamento de benefícios do regime geral de previdência social. Dessa forma, os recursos para financiamento da saúde passaram a depender de aportes gerais do orçamento da seguridade social, cujas fontes financeiras principais eram recursos tributários e fiscais, dentre os quais os mais expressivos são a Contribuição para o Financiamento da Seguridade Social (COFINS) e a Contribuição Social sobre o Lucro Líquido (CSLL) e, a partir de 1993, da participação mais relevante do Tesouro da União (SENADO FEDERAL, 2013).

8 Sobre o tema da criação de tributos para custeamento da saúde, vale citar Harada (2011). 


\title{
2.4 A Sobrecarga do Financiamento Municipal dos Serviços Públicos de Saúde
}

A doutrina sobre o tema da saúde é rica em artigos e estudos indicando que, apesar de uma crescente participação da União na carga tributária total, seus gastos com saúde crescem numa proporção relativamente menor, cada vez mais ficando o ônus do custeio com os Municípios. Isso está ligado com a estrutura normativa formada. Nesse sentido, como já exposto, o texto original da $\mathrm{CF} / 88$ nada dispunha sobre valores mínimos a serem investidos em saúde, tendo sido tal tema tratado apenas a partir da Emenda Constitucional $\mathrm{n}^{\mathrm{o}} 29$, de 2000, que, diante do já relatado cenário de poucos recursos, incluiu no texto o art. 198, parágrafo $2^{\circ}$, do Art. 198. Nesse sentido:

\begin{abstract}
Ao invés de indicar diretamente quais patamares e/ou percentuais deveriam ser aplicados como referência de vinculação orçamentária de gasto mínimo, o parágrafo $2^{\circ}$ do Art. 198 da Constituição estabeleceu apenas o dever genérico de tal gasto mínimo. A bem da verdade, no citado dispositivo, foram apontadas apenas as bases de cálculo relativas aos Estados, DF e municípios sobre as quais deveriam incidir os programáticos percentuais. Não houve indicação de qualquer critério objetivo para a União nem de percentuais vinculantes para os demais entes. Tudo isso fi cou relegado a tratamento posterior em lei complementar, na forma do parágrafo $3^{\circ}$ do Art. 198 da Constituição. É dessa omissão deliberada (na forma do Art. 198, § 3), que durou até a regulamentação da Lei Complementar $n^{\circ} 141 / 12$, que se alimentou a instabilidade fiscal da política pública de saúde e a guerra fiscal de despesa que, desde então, tem sido vivenciada no setor entre os três níveis da federação. (PINTO, FLEURY, p. 70).
\end{abstract}

Assim, no tocante a fixação de pisos de gastos, na EC n 29 limitou-se a criar uma regra temporária, inserida no art. 77 do Ato de Disposições Constitucionais Transitórias, segundo a qual deveriam ser aplicados, ao menos, $12 \%$ da receita corrente líquida para Estados e $15 \%$ para Municípios. Já a União ficou ainda mais dependente de regulação posterior, devendo apenas por hora alocar, em 2000, 5\% a mais do que em 1999 e nos anos seguintes devendo aplicar correção nominal conforme a variação do Produto Interno Bruto.

Essas regras de transição teriam vigência até 2004, quando deveria ter sido editada lei complementar para estabelecer/revisar novos percentuais mínimos de aplicação em ações e serviços públicos de saúde, os critérios de rateio dos recursos da União aos outros entes, as normas de fiscalização, avaliação e controle dos gastos com saúde, e as normas para cálculo do montante a ser aplicado pela União. 
É importante observar que a Emenda previa, em sua essência, dois critérios diferentes para a correção dos valores mínimos a serem aplicados pela União e pelas demais esferas federativas: enquanto os mínimos a serem aplicados pela União deveriam ser aumentados conforme a variação do PIB, os demais mínimos deveriam ser incrementados com base na variação da arrecadação tributária. Esse fato é relevante pois durante o período relevante o PIB cresceu em taxa mais lenta que a do aumento da receita tributária (nesse sentido, a variação nominal do PIB entre, por exemplo, 2001 e 2010, foi de 212,32\%, ao passo que a variação da arrecadação tributária foi de $264,46 \%{ }^{9}$ ), o que causou com que a cada ano a proporção de recursos alocados pela União fosse ficando menor.

Desse modo, usando o mesmo período de comparação do parágrafo anterior, tem-se que em 2001 a contribuição de recursos para a saúde era de 56,1\% para a União, 20,7\% para os Estados e 23,2\% para os Municípios. Já em 2010 era de 44,1\% para a União, 26,5\% para os Estados e 29,4\% para os Municípios (PIOLA, 2013). Como se percebe, em termos relativos há regressão dos dispêndios federais somada a incremento dos gastos municipais.

Já sobre o montante geral de gasto público em saúde sobre percentual do PIB, observe-se que aumentou em quase 1 ponto percentual no período sob exame (de 3,08\% para $3,73 \%$ ) (PIOLA, 2013). Como se infere pelas proporções, isso se deu pela maior parte pelo aumento das participações dos Estados e Municípios.

Cumpre reiterar que por um longo período, entre a EC nº 29/2000, e a edição da recente $\mathrm{EC} \mathrm{n}^{\circ}$ 86/2015, não houve nenhuma correlação entre o comportamento progressivo da receita federal com o seu volume de gastos no SUS, haja vista que o critério normativo de gasto mínimo a ser vertido pelo Governo Federal para as ações e serviços públicos de saúde (ASPS) sempre cuidou de manter o patamar do ano anterior corrigido tão somente pela variação nominal do PIB, o que teve como consequência o estabelecimento de uma vinculação estagnada do gasto federal em saúde.

Destarte, apenas a partir do exercício de $2016^{10}$ com a Emenda Constitucional no ${ }^{\circ} .86$, que a União passou a ter compromisso de gastar porcentual incidente sobre sua receita corrente líquida, e mesmo assim, haverá escalonamento de índices mínimos ditos

\footnotetext{
9 Dados obtidos em https://impostometro.com.br/. Acesso em 19/04/2017.

${ }^{10}$ Apenas a $E C \mathrm{n}^{\circ}$. 86/2015 do orçamento impositivo finalmente fixou o piso de aplicação da União: a partir de 2016, 13,2\% crescendo até chegar em 15\% da RCL em 2020.
} 
"progressivos", para que - em 2020 - seja possível chegar ao novo patamar de $15 \%$ da receita corrente líquida federal para a política pública de saúde (PINTO, 2015) ${ }^{11}$.

Contudo, com a promulgação da $n^{\circ}$ 95/2016, que institui o Novo Regime Fiscal de limitação de gastos por vinte exercícios financeiros, limitando o incremento global das despesas, há forte receio de que serão insuficientes os recursos federais para a saúde, pelo retorno da situação descrita na seção 2.3, na qual o aumento acentuado das despesas de previdência faria com que estas tomassem os recursos que seriam da saúde. Isso porque havendo o congelamento do total das despesas, e com a previdência tendo um crescimento vegetativo natural, tal resultado seria inevitável sem um aumento das receitas, revisão da regra constitucional de reforma, ou reforma previdenciária.

Assim, a situação de insuficiência de recursos para saúde que perdura desde 1988 (para não se falar de antes), só seria regularizada a partir de 2020 - e isto se as normas de reforma fiscal o permitirem. Diante desse quadro de constante falta de aplicação de verbas federais em direito fundamental social de tal grandeza, apesar de ser necessária cautela e autorestrição ao se ponderar o princípio da vedação a proteção insuficiente, não se pode deixar de concluir que a União está deixando de realizar a prestação de serviços adequada ${ }^{12}$.

\section{CONFLITO GERENCIAL NA PRESTAÇÃO DE SERVIÇOS PÚBLICOS DE SAÚDE: UNIÃO X ESTADOS E MUNICÍPIOS}

Preliminarmente, cabe tecer esclarecimentos sobre como está estruturada a divisão de competências entre os entes federativos no âmbito do SUS. Em termos gerais, são as seguintes atribuições: à União cumpre planejar e fiscalizar a política nacional de saúde; repassar verbas aos Estados e Municípios; coordenar os atendimentos de alta complexidade e os laboratórios públicos; transferir medicações complexas. Já aos Estados compete adaptar a política nacional de saúde às peculiaridades regionais, coordenando as ações em seus Municípios; repassar verbas aos Municípios; gerenciar e prestar os atendimentos de alta complexidade e média complexidade. Por fim, aos Municípios resta prestar serviços de

11 Disponível em: http://www.conjur.com.br/2015-abr-04/elida-pinto-descompasso-federativo-financiamentosaude.

12 As constatações sobre como em 1988 se fez uma determinada divisão federativa de recursos e responsabilidade, a qual está tendo de ser revista de forma periódica e inevitável, levam inevitavelmente a conclusão de que carece, como base do pacto federativo brasileiro, uma análise quantitativa e qualitativa realista de como dividir as competências, havendo, portanto, o vício de irracionalidade. 
atenção básica na localidade (prevenção, primeiros socorros e procedimentos ambulatoriais e hospitalares simples).

A proposta por trás dessa divisão é de que a administração local, conhecedora dos problemas de sua região e com a experiência das práticas lá já adotadas, pode exercer a gestão tática da melhor forma. Já a União e os Estados, com maior conhecimento técnico e uma visão ampla, desenhariam as melhores respostas em abstrato e dariam apoio aos Municípios em sua implantação e especificação local.

Outro ponto que merece destaque, e já pode se vislumbrar nas explicações acima, é a divisão da prestação de serviços em três níveis de complexidade, básica, média e alta.

A atenção básica ou primária constitui o primeiro nível de atenção à saúde. Nos termos da Portaria no . 2488/2011 do Ministério da Saúde, que aprovou a atual Política Nacional de Atenção Básica, é o conjunto de ações de saúde, no âmbito individual e coletivo, que abrange a promoção e a proteção da saúde, a prevenção de agravos, o diagnóstico, o tratamento, a reabilitação, redução de danos e a manutenção da saúde com o objetivo de desenvolver uma atenção integral que impacte na situação de saúde e autonomia das pessoas e nos determinantes e condicionantes de saúde das coletividades.

Como em todo o SUS, essa atenção básica se dá com a coordenação da União, que define os programas e estratégias gerais, e com a execução dos serviços pelos Municípios. Os serviços de saúde da atenção primária são prestados principalmente nas Unidades Básicas de Saúde, que são a porta de entrada preferencial do SUS e têm o objetivo de atender a maioria dos problemas de saúde da população sem que haja a necessidade de encaminhamento para outros serviços de maior complexidade, tais como emergências e hospitais. Já a garantia de acesso aos procedimentos de maior complexidade é de responsabilidade solidária entre o Ministério da Saúde e as Secretarias de Saúde dos Estados e do Distrito Federal, podendo a média e alta complexidade ser realizada pelos municípios mediante pactuação ${ }^{13}$.

Como se pode perceber, diversas atividades competem aos Municípios, especialmente na prestação direta de serviço ao cidadão, em contraste com a conhecida participação reduzida que estes entes federativos têm na repartição dos tributos arrecadados.

\footnotetext{
${ }^{13}$ Explica-se que essa foi a base de constituição do SUS, com estrutura de saúde descentralizada. Isso se deu inclusive pela necessidade inicial de formar a gestão dos Municípios na prestação dos serviços públicos de saúde, ampliando a sua participação. Além disso, havia o interesse de tutelar os entes municipais por desconfiança deles, e pela necessidade de formar um sistema de porta de entrada interoperável, no qual todos os órgãos de atenção básica conseguissem harmonicamente levar os mesmos de atenção média-alta
} 
Passando a examinar a operacionalização das transferências governamentais para saúde, o principal aspecto para este estudo, e o mais importante em geral, é que se dividem em dois grandes tipos: os convênios e as transferências fundo a fundo. Os convênios são acordos negociados entre entes federativos nos quais são definidas destinações e regras para os valores a serem repassados, havendo posterior prestação de contas. Já as transferências fundo a fundo são um mecanismo de repasse automático, no qual os valores são enviados do Fundo Nacional da Saúde para os fundos estaduais e Municipais dando-lhes assim maior autonomia.

Após um momento de experimentação inicial do SUS entre 1988 e 1993, percebeu-se rapidamente as vantagens do sistema de transferências fundo a fundo, por diminuir a burocracia envolvida, aumentar a agilidade, e passar o microgerenciamento dos recursos para as prefeituras municipais, entes mais apropriados. Assim, para superar a falta de uma legislação inicial que impediam que essas transferências ganhassem força (na tramitação legislativa da Lei Federal $n^{\circ} .8 .080 / 90$, que disciplina a política nacional de saúde, os artigos relacionados foram vetados, restando apenas o art. 35), foi editada a Lei Federal $n^{\circ}$. 8.142/90, e editadas as Normas Operacionais Básicas do SUS (NOB-SUS 1/91, 1/93, e 1/96) que definiram o sistema de habilitação - conjunto de níveis de exigências e responsabilidades que um Município deve cumprir para passar a receber os repasses automáticos. O resultado foi um enorme sucesso, com rapidamente quase todos os Municípios aderindo em algum nível de habilitação.

Para aprimorar o sistema, foi editada a Portaria MS nº. 204/2007, a qual estabeleceu que as transferências fundo a fundo de recursos federais seriam dentro de um conjunto de seis contas únicas e específicas diferenciadas por bloco de financiamento (atenção básica, atenção de média e alta complexidade, vigilância em saúde, assistência farmacêutica, gestão do SUS, e investimentos na Rede de Serviços de Saúde).

Contudo, apesar desse avanço e sucessos no sistema de fundo a fundo, continuava forte, e em diversos casos predominantes, os repasses por convênio. Isso porque o sistema de convênios permite que a União atue, em boa parte, direcionando os municípios para que realizem os programas que crê mais necessários. Por exemplo, a partir da decisão técnica da União de que os municípios deveriam focar seus serviços em agentes comunitários da saúde foi desenvolvido o atual Estratégia Saúde da Família, ao qual as prefeituras podem aderir por convênio e passam a fazer jus a verbas relacionadas. Evidentemente, como os gestores municipais desejam prestar serviços para seus eleitores, há grande adesão ao programa; mas 
se as verbas fossem repassadas fundo a fundo, a União não teria nenhuma ingerência em onde seriam aplicadas.

Essa relação de direcionamento indireto da União, conhecida por alguns como “descentralização tutelada", é não somente um fenômeno forte, mas também de penetração crescente na prestação pública de serviços de saúde no Brasil. Na atenção básica, por exemplo, enquanto em 1995 os valores transferidos fundo a fundo ("PAB-fixo") pelo Ministério da Saúde a municípios correspondiam a 9\% dos gastos daquele órgão com saúde e os valores oriundos de convênio ("PAB-variável") eram 1\%, em 2010 já haviam passado para $5 \%$ com fundo a fundo e $9 \%$ com convênio (PIOLA, 2013).

Tal variação não parece desejável. Os convênios deveriam ser usados como exceção, pois estão intimamente ligados com microgerenciamento excessivo pela União e consequente prejuízo a eficiência e efetividade dos serviços públicos de saúde. Assim, deveriam ser aplicados apenas em projetos estratégicos especiais, que façam parte do núcleo de uma política pública nacional de qualidade, e ainda dotados de maior estabilidade para diminuir as incertezas que afligem as prefeituras sobre os futuros fluxos de recursos.

Um outro aspecto de crítica da sistemática de transferências é que, mesmo no sistema fundo a fundo, a existência dos seis blocos representa enfaixamento dos gestores municipais, eis que, por exemplo, não podem alocar recursos de investimentos ou assistência farmacêutica para atenção básica ou vigilância, por exemplo. Para amenizar isso, está sendo debatido um novo modelo de repasses chamado "SUS Legal", no qual haveria apenas duas modalidades de repasse, o custeio e o financiamento, e eliminaria ainda formas alternativas de remessa. Tal possibilidade aparenta ser vantajosa, apesar de ainda ser incerto suas consequências efetivas, inclusive por não terem sido suficientemente especificados os detalhamentos.

Em síntese, essa é a essência da disputa gerencial entre União e municípios. Primeiro, estes têm menos autonomia para decidir, mesmo sendo quem conhecem melhor os problemas da população local. Segundo, não têm segurança quanto a eventual interrupção de programas, situação que representa um perigo natural num sistema presidencialista e que pode ser desastroso quando já houve admissão de servidores. De qualquer sorte, considerando o universo de 5.500 municípios, muitos deles de pequeno porte, longínquos e com graves deficiências de gestão, não se entende por desarrazoada a interferência da União.

\section{CONSIDERAÇÕES FINAIS}


A vigência da Constituição Federal de 1988 até essa quadra da história, em concomitância com a gestação e desenvolvimento do SUS, tem demonstrado que o arranjo normativo de financiamento dos serviços públicos de saúde apresenta constantes impasses que levam ao subfinanciamento. Essa conjuntura resulta em profundas distorções federativas entre Municípios, Estados e União, sendo que os primeiros passam a suportar a sobrecarga de demandas sem correspondente fonte de receitas.

Tal desiquilíbrio do financiamento atual pode ser, em boa parte, rastreado até a normatização insuficiente, pois desde a Emenda Constitucional nº. 29/2000 havia mínimos de aplicação para os municípios em elevados percentuais de receita tributária, ao passo que para a União bastava aplicar o mesmo valor que no anterior com correção pelo crescimento econômico - sendo que há tendência para que o crescimento da arrecadação seja maior que o dos impostos. Assim, havendo critérios diferentes, e bastante mais onerosos para os municípios que para a União, ocorreu como resultando uma alteração no nível de ônus suportado por cada um.

Finalmente, a Emenda Constitucional n'. 86/2015 parecia corrigir tal discrepância, ainda que só passasse a operar efeitos plenos a partir de 2020. Contudo, a crise fiscal do Estado somado ao Novo Regime Fiscal instituída pela Emenda Constitucional nº 95/2016 impedirá tais efeitos, pois o crescimento vegetativo dos gastos da previdência num ambiente de teto global dos gastos levará que o orçamento da seguridade social passe a estar cada vez mais comprometido apenas com a previdência. Para impedir isso, é necessário que aumentem as receitas, ou seja abolido o teto dos gastos, ou sejam diminuídas as despesas previdenciárias.

Além disso, a estruturação do SUS atual gera deficiências de gestão pelo conflito entre União e municípios, numa tensão ainda sem equilíbrio entre controle e autonomia. Um primeiro e importante passo é limitar os convênios para poucas situações, e não ser o principal método de repasses. Além disso, para evitar o problema da descontinuidade, os convênios estratégicos que se opte por manter deveriam ter garantias adicionais de estabilidade, evitando que municípios se comprometam com despesas de pessoal que depois não possam arcar.

Quanto às transferências fundo a fundo, o sistema de seis blocos também representa ingerência excessiva e gera disfunções inevitáveis, com recursos concretamente excedentes num bloco e faltando em outro conforme realidades locais. Nesse sentido, a proposta de mudança para um sistema de dois blocos parece salutar - ainda que, por inevitável, eventuais consequências negativas só serão conhecidas após a implantação prática. 


\section{REFERÊNCIAS}

ALCEU, Maurício Jr. A revisão judicial das escolhas orçamentárias: a intervenção judicial em políticas públicas. Belo Horizonte: Fórum, 2009.

BRASIL, Constituição da República Federativa do Brasil. (Brasília, DF: Senado Federal, 1988). Disponível em: <http://www.planalto.gov.br/ccivil_03/constituicao/constituicao.htm>. Acesso em: 15 mai. 2017.

Emenda Constitucional n ${ }^{\circ} 29$, de 13 de setembro de 2000. Altera os arts. 34, 35, 156, 160, 167 e 198 da Constituição Federal e acrescenta artigo ao Ato das Disposições Constitucionais Transitórias, para assegurar os recursos mínimos para o financiamento das ações e serviços públicos de saúde. Disponível em: < http://www.planalto.gov.br/ccivil_03/constituicao/emendas/emc/emc29.htm>. Acesso em: 30 abril 2017.

Senado Federal. COMISSÃO TEMPORÁRIA DESTINADA A PROPOR SOLUÇÕES AO FINANCIAMENTO DO SISTEMA DE SAÚDE DO BRASIL - CTS. Disponível em: < http://legis.senado.leg.br/comissoes/comissao?0\&codcol=1587>. Acesso em 05/05/2017.

BONAVIDES, Paulo. Curso de Direito Constitucional. 31. ed. São Paulo: Malheiros, 2016.

CNM - CONFEDERAÇÃO NACIONAL DOS MUNICÍPIOS. A Política de Financiamento do SUS numa Ótica Municipalista. Disponível em < http://www2.camara.leg.br/atividadelegislativa/comissoes/comissoestemporarias/especiais/55a-legislatura/pec-001-15-percentualminimo-para-a-saude-18-7/documentos/audiencias-publicas/fabia-almeida-richter-prefeita-decristal-rsrepresentando-a-confederacao-nacional-dos-municipios-cnm>. Acesso em 19-052017.

HARADA, Kiyoshi. Financiamento do setor de saúde. É preciso novo tributo?. In: JAM Jurídica. Ano 16, n. 11, novembro, 2011.

HACHEM, Daniel Wunder. A maximização dos direitos fundamentais econômicos e sociais pela via administrativa e a promoção do desenvolvimento. In: Revista de Direitos

Fundamentais e Democracia. Curitiba, v. 13, n. 13, p. 340-399, janeiro/junho de 2013.

HOLMES, Stephen; SUNSTEIN, Cass. The Cost of Rights - Why Liberty Depends on Taxes. Nova York: W. M. Norton, 1999.

MIRANDA FILHO, Aloysio Meirelles de. A saúde pública e o seu financiamento. In: Revista dos Tribunais: Cadernos de Direito Tributário e de Finanças Públicas. São Paulo, ano 3, n. 12, julho-setembro de 1995.

PIOLA, Sérgio F. et al. Financiamento Público da Saúde: uma História à Procura de Rumo. Rio de Janeiro: Ipea, 2013. 
PINTO; Élida G; FLEURY, Sonia. Custeio do direito à saúde: em busca da mesma proteção constitucional pelo direito à educação. In: RDisan, São Paulo. v. 12, n. 3, p. 54-80. Mar./Jun. 2012.

PINTO, Élida Graziane. Descompasso federativo no financiamento da saúde pública brasileira. Disponível em: <http://www.conjur.com.br/2015-abr-04/elida-pinto-descompassofederativo-financiamento-saude>. Acesso em: 30/04/2017.

PUGIN, Simone Rossini; NASCIMENTO, Vânia Barbosa do. Principais Marcos das Mudanças Institucionais do Setor Saúde. Cedec, 1996. Disponível em: $\langle$ http://www.cedec.org.br/files pdf/didatil.pdf $>$. Acesso em 14/05/2017. 